\title{
Oral Paste Dosage Form
}

National Cancer Institute

\section{Source}

National Cancer Institute. Oral Paste Dosage Form. NCI Thesaurus. Code C91170.

A paste intended for administration through the mouth. 